\title{
The Influence of Clinical Supervision of Therapists in the Therapeutic Alliance Between Patient and Therapist
}

\author{
Fleischer NI* \\ Four Bridges Social Work Services, Staten Island, NY, USA
}

\begin{abstract}
The therapeutic alliance between patient and Clinical Social Worker/Therapist is directly influenced by clinical supervision that therapists receive. This article will bring awareness to Clinical Supervisors' abilities to correct and adjust to how they are providing Clinical Supervision or how Clinical Social Workers are receiving supervision.
\end{abstract}

Keywords: Therapist, Patient, Social worker, Supervision

The Influence of Clinical Supervision of Therapists in the Therapeutic Alliance Between Patient and Therapist

I entered into the field of Social Work believing I will learn to incorporate my supervisors' teachings while exploring my own philosophy and style. But I quickly learned that the outcome of successful treatment between the patients I was treating and myself as their therapist was influenced heavily by what my supervisors were teaching me from their subjective perspectives. Supervisors throughout the years have attempted to manipulate my own philosophy and style to their way of thinking. If I dared asked questions about how they thought or felt about their insight and experiences, there would have been consequences for me. I asked them to please guide me in compartmentalizing my emotions stemming from certain cases. Then too I was notified of potential consequences. Overall, supervisors were teaching me about their personal beliefs in professional alliances between myself and the people I was providing services for. And when each time I wanted to learn from all of my supervisors how to think independently as well as tap into their treasure trove of knowledge and expertise, I received career development roadblocks in my supervisions with them. I realized if I wanted to succeed in my career and not suffer consequences in the form of losing jobs, I had to learn how to keep my mouth shut. I learned immediately then and there on asking only those questions that I knew my supervisors wanted me to ask. I listened and followed their guide meticulously. The potential for consequences were eliminated, my jobs remained consistent, and my potential grew exponentially.

However, I began to notice that my psychotherapy sessions were becoming personal platforms for my clinical supervisors to promote their philosophies and beliefs about what the outcome of patient's treatments should be. Their voices were vicariously through clinical supervision with me influencing my sessions with my patients. I began to internalize and doubt my level of professionalism specifically regarding developing expertise and my pro-

\begin{tabular}{|l|l|}
\hline \hline Quick Response Code: & Forresponding author: Nanette I Fleischer, Four Bridges Social Work Services @ 88 New \\
Dorp Plaza, Staten Island, NY, USA \\
Received: 13 September, 2021
\end{tabular}


vision of services when treating my patients. I noticed patients too beginning to internalize negativity more so than when they entered treatment initially.

When I asked my supervisors about perhaps adjusting my interventions based on alternative theoretical perspectives I had learned, I was immediately ridiculed and criticized by my supervisors, who were also the very people entrusted in my clinical professional growth following graduation with my MSW. They were overly non-constructively critical, accusatory, and blamed me for all issues that were challenging in my caseload. I was told I would not professionally succeed in the field of Social Work because I was being considered a non-team player. This was so only when I asked questions of my supervisors about what they were teaching me. The more I wanted to help my patients learn the change processes and reduce their symptoms, the more I desperately wanted to ask my supervisors questions about it and how to apply theory to practice. I refrained, however. Those supervisors had wanted me to believe that the content and outcome of supervision they were providing to me had absolutely no influence on the therapeutic alliance between my patients and myself.

I began questioning myself because I wanted desperately to learn also how to compartmentalize and curtail any countertransference's I was unaware of. After all, I was in the infancy of my Social Work career at that time. They ignited negativistic flames in my thinking about myself personally and professionally. This thinking influenced my clinical abilities when I truly began to believe them where self-doubt turned to my questioning even remaining in this field. I truly began to contemplate whether I was igniting fears of crises for my patients because I was not receiving proper clinical supervision.

Fortunately, I was told by countless other professionals at that time, including professors and many of my colleagues that I was not receiving proper supervision as they believed I should have been. I decided right there and then that I was resilient and refused to accept defeat. I decided not to leave this wonderful and illustrious field of Social Work. Therefore, I decided to seek outside supervision who had emphatically assisted me in learning about therapeutic alliances in psychotherapy. I hired outside supervisors to answer the questions I had about my cases that I knew my agency supervisors did not desire to ever discuss nor address because they did not want me to think objectively. Only then had the outcome to my patients' treatments become more prosperous and productive. I learned that those agency supervisors were wrong for not permitting me to learn, grow, develop, and think both independently and professionally. In looking back, I was right to just not agree with them. I did not think that I was inappropriate nor off base to ask those kinds of questions. In my outside supervisions, I became more confident in myself as a person and so much more competent as a developing professional Clinical Social Worker.
Patients are unaware of outside influences affecting their treatment and begin to perceive their own emotions as fraught with unyielding consequences if therapists are not aware of this to address this as it arises during treatment sessions with patients. My patients in general did not realize that I had poor clinical supervision affecting the outcome of their treatments. My patients needed to minimize or eliminate negative consequential challenges such as issues, symptoms, or behaviors. But I learned that therapists could convey faulty skills stemming from negative influences from supervision. And that these faulty skills could become a conditioning factor that is then reinforced as actual knowledge gained in supervision. I want this to end now. I want to bring attention to this issue in this article since I believe I am not the only Social Worker to have experienced this. I want to begin to have Social Worker's learn and not fear what it entails to compartmentalize rather than suppress personal thoughts and feelings about their cases when addressing this in supervision with their supervisors. Improvement in the supervisory process is also what I would want to see as a positive result from my writing this article.

Even though I disagreed with these agency supervisors, I decided to remain silent about my own thoughts. I listened to them because I did not want to be considered argumentative. I readjusted my questions of my supervisors accordingly because in fact I was and still am a team player. I followed every detailed instruction without question. And I succeeded in order to flourish in my career. In essence, I learned the art of success through suppression in supervision with my supervisors and used outside supervision to make sure that my patients would not be affected by my being new to the field of psychotherapy.

If therapists are not receiving clinical nor objective direction in supervision, their patients' symptoms could evolve. Symptoms could vary due to their therapist's unawareness of their countertransference's or because they are not learning how to provide appropriate interventions. Social Workers are reliant upon their supervisors to ask questions about situations they are confronted with in order to prevent this from occurring. Supervision is just the place to receive these answers. These answers could begin preventing patients' symptoms from continuously assaulting them. These answers could help therapists treat patient's pathological cognitions that is challenging for new therapists to treat psychotherapeutically.

When patients engage in Social Work services, I feel that they want to overcome personal conflicts and crises in order to embrace positive change. When patients enter into therapy, as an example from my own clinical expertise, they are attempting to turn the tides of circumstances stoking their crises. It is the therapist's job therefore to assist their patients in believing that they are going to do just that. However, often this has not been the case because of the supervision therapists are receiving. I believe patients could 
have reactionary behaviors in the form of fear for those with therapists who are influenced negatively by their supervisors for not receiving adequate or appropriate supervision. Patients' fears would then turn into frustration, agitation, and resentment. Rationalizations in the form of reactionary behaviors on the part of patient's could manifest. Patients' emotions and cognitions, already riddled with adverse behaviors, could develop into even more pathological coping mechanisms. These patients' issues I believe would become a cascade of symptoms snowballing out of control.

Change as the patient desires would become unachievable. Patients subsequently would become discouraged from self-empowering, self-reflecting, and/or self-discovering. Treatment itself can conflict with positive attitudes toward improvement. Patient's mental/behavioral health issues or concerns could become exacerbated when therapists begin to believe that patients are resistant and oppositional. Patients' emotions of fear could be ignited from internalizations. These emotions could intertwine with the other deeply rooted pathological feelings and thoughts that brought patients to seek therapy in the first place.

If these pathological emotions normalize, they could remain very prevalent in patient's negativistic thought processes regarding their own self-efficacy in my opinion. This occurs because of the fact that people are afraid of the unknown from my perspective and are also afraid of fear and of change. Therapists' own fears could then develop from their patient's symptoms and evolve into low frustration tolerance and stimulated aggressive reactions within themselves. Patients could become further vulnerable and influenced by their therapists' negativistic attitudes and reactions in their sessions. Internal conflicts could further develop for both therapists and their patients when therapists have similar fears and thoughts to their patients. Some patients could even mimic their therapists believing this was positive change for themselves. Patients could then interpret therapists' thoughts as their own. Both patients' and their therapists' fears all together become exacerbated without either understanding why. Survival becomes questionable for patients without appropriate intervention from their therapists. In all of those scenarios, neither does the patient benefit from treatment nor does the therapist benefit from clinical and professional development from supervision. This is not the kind of change that I believed patients truly are seeking when engaging in the therapeutic alliance. Yet, this in my opinion, is not uncommon and a phenomenon.

My story is what I believe many Social Workers are currently experiencing. This could be the reason why so many people are influenced to believe something different than what they thought was true about themselves. Cascading negativity in supervisions negatively influences and affects outcomes of treatment for countless patients in my opinion. I needed a positive influence in clinical supervision with my supervisors and not one that was critical without a road map for me to learn by and be guided by. Patients expect to experience professionalism, knowledge, expertise, insight, direction, and provision of services to help them decrease symptoms and improve their lives. But as I was learning and developing my skills in supervision early in my career, my patients had little if any input into the outcome from their own therapy sessions because of what I was being taught in supervision. Even so, I did not for one minute ever believe that providing professional knowledge, expertise, insight, direction, and provision of services could ever occur without appropriate therapeutic alliances. And what I soon began realizing, was just how wrong my supervisors were. The art of the therapeutic alliance in psychotherapy is a basic tenet in the successful outcome of any psychotherapeutic treatment. Therefore, I differed with their ideology.

When I finally hired and obtained the good outside clinical supervision, they helped me deal with those circumstances and helped me to affect a positive outcome of treatment for my patients as I forged forward in my career. This was so imperative. Therapeutic alliances developed appropriately with successful outcomes of treatment for my patients. In my opinion, those former supervisors were less qualified and not prepared for the role of what it entailed to be good at providing supervision. I am however a better person and therapist today over 15 years later now because of them and because of those experiences.

I am certain there are Social Workers out there unaware of their supervisors' influence on them presently. They might not have the means nor time to obtain outside supervision as I had. It is imperative therefore that those entrusted to provide any kind of Social Work supervision has expertise that includes their admitted influence over their role as Supervisor regarding the outcome of services their Social Work staff are providing to patients. I have always stayed true to my understanding, nevertheless, never taking for granted the influence that supervision had in my professional alliance between myself and my patients. I believed then and still do to date that the therapeutic alliance is significant to the outcome of therapy. And that my story is a phenomenon that I believe needs to be addressed head on to prevent it from occurring any further. Therapists and the clinical supervisors overseeing therapy cases should assist in empowering patients to take active roles in therapeutic processes and in therapeutic alliances to achieve successful outcomes in therapy. Therapists should then also teach their patients how to achieve good problem-solving techniques. This in turn improves the outcome of therapy and development of the therapeutic alliances by promoting respect all around.

I hope that this article will permit others new and already in this field to stay true to the basic tenets of human kindness and courage with professionalism by holding your heads up high and 
know and believe that you are better than any moment of despair as you progress in your careers. This is regarding your futures if you too are ever confronted and challenged as I was with poor supervision. Never permit this however to interfere with your work psychotherapeutically with patients or provision of services for your patients. Patients' treatments should never be compromised by agency bureaucratic red tape. I learned lessons regarding what to do and what not do, as I approach clinical supervision as an experienced Psychotherapist for over 15 years now. I use these lessons as tools when teaching future clinicians and current therapists about the influence I have on them in their clinical supervision regarding their therapeutic alliances with their patients. This is such a wonderful and dynamic field filled with possibilities. Let us each embrace our personal selves but never allow it to alter the beauty of objectivity and individuality in the Clinical Supervision we provide to the next generation of Clinical Social Workers.

\section{Acknowledgments}

None.

\section{Funding}

None.

\section{Conflicts of Interest}

The authors declare no conflicts of interest. 